\title{
Increased NK cell maturation in patients with acute myeloid leukemia
}

\begin{abstract}
Anne-Sophie Chretien ${ }^{1 *}$, Samuel Granjeaud ${ }^{2 \dagger}$, Françoise Gondois-Rey ${ }^{1,3 \dagger}$, Samia Harbi ${ }^{4}$, Florence Orlanducci ${ }^{2}$, Didier Blaise ${ }^{1,4}$, Norbert Vey ${ }^{1,5}$, Christine Arnoulet ${ }^{1,6}$, Cyril Fauriat ${ }^{1}$ and Daniel Olive ${ }^{1,2}$

${ }^{1}$ Centre de Cancérologie de Marseille, Team Immunity and Cancer, INSERM, U1068, Institut Paoli-Calmettes, Aix-Marseille Université, UM 105, CNRS, UMR7258, Marseille, France, ${ }^{2}$ Centre de Cancérologie de Marseille, Systems Biology Platform, INSERM, U1068, Institut Paoli-Calmettes, Aix-Marseille Université, UM 105, CNRS, UMR7258, Marseille, France, ${ }^{3}$ Centre de Cancérologie de Marseille, Plateforme d'Immunomonitoring en Cancérologie, INSERM, U1068, Institut Paoli-Calmettes, Aix-Marseille Université, UM 105, CNRS, UMR7258, Marseille, France, ${ }^{4}$ Hematology and Transplant and Cellular Therapy Department, Institut Paoli-Calmettes, Marseille, France, ${ }^{5}$ Hematology Department, Institut Paoli-Calmettes, Marseille, France, ${ }^{6}$ Biopathology Department, Institut Paoli Calmettes, Marseille, France
\end{abstract}

Understanding immune alterations in cancer patients is a major challenge and requires precise phenotypic study of immune subsets. Improvement of knowledge regarding the biology of natural killer (NK) cells and technical advances leads to the generation of high dimensional dataset. High dimensional flow cytometry requires tools adapted to complex dataset analyses. This study presents an example of NK cell maturation analysis in Healthy Volunteers (HV) and patients with Acute Myeloid Leukemia (AML) with an automated procedure using the FLOCK algorithm. This procedure enabled to automatically identify NK cell subsets according to maturation profiles, with 2D mapping of a four-dimensional dataset. Differences were highlighted in $\mathrm{AML}$ patients compared to $\mathrm{HV}$, with an overall increase of NK maturation. Among patients, a strong heterogeneity in NK cell maturation defined three distinct profiles. Overall, automatic gating with FLOCK algorithm is a recent procedure, which enables fast and reliable identification of cell populations from highdimensional cytometry data. Such tools are necessary for immune subset characterization and standardization of data analyses. This tool is adapted to new immune cell subsets discovery, and may lead to a better knowledge of NK cell defects in cancer patients. Overall, 2D mapping of NK maturation profiles enabled fast and reliable identification of NK cell subsets.

\section{Keywords: AML, NK maturation, automated gating, FLOCK algorithm, multidimensional flow cytometry}

\section{INTRODUCTION}

Natural Killer (NK) cells are immune effectors that play a key role in tumor rejection, with an ability to detect and lyse tumor cells without prior stimulation (1-3). Their fundamental role in anti-tumor immune response has been widely demonstrated in both solid tumors and malignant hemopathies, and parameters linked to NK cell activation can either be prognostic factors (4-9) or predictive markers of response to chemotherapy or radiotherapy $(10,11)$. Thus, monitoring NK cell parameters seems to be an important point to stratify patients at diagnosis and to assess NK cell response during the course of treatment. For such applications, NK cell alterations in cancer patients need to be further described in order to dissect mechanisms involved and define the relevant therapeutic strategies based on NK restoration $(12,13)$. 
In addition to classical NK activating receptors, maturation is fundamental for triggering immune response while maintaining self tolerance (14). NK cell maturation and activation are intrinsically linked (14). Therefore, this point is probably of primary importance for NK cell reactivity in the context of malignancies. Recent studies highlight increasing number of markers that define NK cell subsets according to maturation parameters. In mice, some parameters appear as relevant markers to define NK cell clusters according to maturation process, such as CD16 or CD11b, $\mathrm{CD} 27$, and Mac-1, which define NK subsets with progressive acquisition of NK cell effector functions (14-17). In Humans, four parameters further define $\mathrm{NK}$ cell subsets according to the expression of NKG2A, KIR, CD57, and CD56 $(16,18)$. NK cells initially differentiate from immature CD56 ${ }^{\text {bright }}$ to $\operatorname{CD} 56^{\text {dull }}$ phenotype, with different functions, including cytotoxicity, cytokine production, and migratory capacities $(14,19,20)$. Subsequently, NK cells lose expression of NKG2A, and sequentially express CD57 and KIR. Accordingly, five states of maturation stages are defined according to expression of these markers.

To date, an increasing number of NK cell activation and maturation markers have been described $(17,21)$. The improvement of knowledge regarding the biology of NK cells led to an increase of markers required to phenotypically and functionally characterize these cells (21). Technological advances in the field of flow and mass cytometry led to the development of complex panels to study NK cells, with subsequent generation of high dimensional dataset (21). In this context, manual processing of the data presents many limitations. First, generation of gates in two dimensions is time-consuming, and subject to operator subjectivity (22). Hence, gating strategy can impact on results and conclusions when multiple gates are drawn [(22); Gondois-Rey et al. manuscript in preparation]. Second, the high number of results generated is sometimes hard to interpret and summarize, in particular when large cohorts of patients are analyzed. Another problem is the global comprehension of a complex system and interpretation of results when conclusions are drawn parameter by parameter. New tools are then required to address these problems. Recently, algorithms for automatic gating and 2D mapping of high dimensional dataset have been developed, such as Spade (23), viSNE (24), flowClust $(22)$, or FLOCK $(25,26)$. These algorithms combined to classification methods enable the visualization of multiple parameters and summarize information. These approaches are of particular importance to enable data visualization, in particular in the context of study of complex systems such as immunity. The present study is an example of application of NK maturation profiling in Healthy Volunteers (HV) and patients with Acute Myeloid Leukemia (AML) using automated analysis of flow cytometry data.

\section{PATIENTS AND METHODS}

\section{Patients and Healthy Volunteers}

Fresh peripheral blood samples were prospectively collected from AML patients $(N=18)$ at diagnosis before induction chemotherapy and from aged-matched healthy volunteers $(N=18)$. All participants gave written informed consent in accordance with the Declaration of Helsinki. Patients above 65 years at diagnosis were excluded. The entire research procedure was approved by the ethical review board (Institut Paoli-Calmettes Marseille, France). Table 1 lists the baseline characteristics of patients.

\section{Flow Cytometry}

A FACS Canto II (BD Biosciences, San Jose, CA, USA) was used for flow cytometry. NK cells from whole blood EDTA were immunostained with Krome Orange-conjugated anti-CD45, Phycoerythrin cyanin 7 (PC7)-conjugated anti-CD3, allophycocyanin (APC)-conjugated anti-CD56, fluorescein isothiocyanate (FITC)conjugated anti-CD158b1b2j, FITC-conjugated anti-CD158a,h (further referred to as KIR), APC-alexafluor 750 (APC AF 750)conjugated anti-CD159 (NKG2A), pacific blue-conjugated antiCD57. All the antibodies used in the study were a kind gift of Beckman Coulter, Marseille, France. Red blood cells were lysed with BD FACS Lysing solution (BD Biosciences) before data acquisition.

\section{Cluster Identification Procedure}

FCS files were read, compensated, transformed, and exported using flowCore (R, Bioconductor) (27). FLOCK algorithm was then applied to each exported data file (26). Resulting gated data were imported with R. Centers of populations were extracted, assembled, and exported as a unique tabulated text file using $\mathrm{R}$. $\mathrm{MeV}$ permitted heatmap visualization and hierarchical clustering (28). Centers were clustered using euclidean distance. The tree of centers was cut at a threshold that results in clusters with homogeneous mean fluorescence intensity (MFI) profile. Those clear populations were annotated using expert knowledge. The automated gating and cluster identification procedure was described by Gondois-Rey et al. (manuscript in preparation).

\section{Statistical Analyses}

Statistical analyses were performed using GraphPad Prism (GraphPad Software, San Diego, CA, USA). Differences in the distribution of continuous variables between categories were analyzed by either Mann-Whitney test (for comparison of two groups) or Kruskal-Wallis with Dunns' post test (comparison of three or more groups). Statistical significance was set at $P<0.05$.

\section{RESULTS}

\section{Automatic Gating with FLOCK Provides Reliable Results}

Multiparametric flow analysis of NK cell subsets has become complex over recent years with the identification of several subsets of NK cells depending on classical activating receptors, inhibitory receptors, and maturation markers. More importantly, it has become evident that rare subsets may be under or overestimated during manual analysis by different investigators and different software. We have, therefore, searched for a more reliable tool to provide unbiased analysis of NK cell subsets in the peripheral blood of AML patients. First, PBMCs from healthy donors $(N=18)$ and AML patients at diagnosis $(N=18)$ were isolated and stained for CD56, CD3, KIR (see PATIENTS AND METHODS), NKG2A, and CD57. Then $\mathrm{CD}^{-}{ }^{-} \mathrm{CD}_{5}{ }^{+}$live $\mathrm{NK}$ cells were 


\begin{tabular}{|c|c|c|c|c|c|}
\hline Characteristic & & All & AML group 1 & AML group 2 & AML group 3 \\
\hline Patients (no.) & $N$ & 18 & 7 & 5 & 6 \\
\hline Age at diagnosis & Mean (SD) & $52.2(13.2)$ & $52.6(14.8)$ & $56.2(7.1)$ & $48.4(16.0)$ \\
\hline Sex ratio, M/F & & 1.57 & 0.43 & 4.00 & 2.00 \\
\hline FAB category & $N(\%)$ & & & & \\
\hline $\mathrm{MO}$ & & $2(11.1)$ & $1(14.3)$ & $1(20.0)$ & $0(0.0)$ \\
\hline M1 & & $5(27.8)$ & $1(14.3)$ & $2(40.0)$ & $2(33.3)$ \\
\hline M2 & & $5(27.8)$ & $2(28.6)$ & $1(20.0)$ & $2(33.3)$ \\
\hline M3 & & $0(0.0)$ & $0(0.0)$ & $0(0.0)$ & $0(0.0)$ \\
\hline M4 & & $1(5.6)$ & $1(14.3)$ & $0(0.0)$ & $0(0.0)$ \\
\hline M5 & & $3(16.7)$ & $2(28.6)$ & $0(0.0)$ & $1(16.7)$ \\
\hline M6 & & $1(5.6)$ & $0(0.0)$ & $1(20.0)$ & $0(0.0)$ \\
\hline M7 & & $0(0.0)$ & $0(0.0)$ & $0(0.0)$ & $0(0.0)$ \\
\hline Unclassified & & $1(5.6)$ & $0(0.0)$ & $0(0.0)$ & $1(16.7)$ \\
\hline Status at diagnosis & $N(\%)$ & & & & \\
\hline De novo & & $13(72.2)$ & $6(85.7)$ & $4(80.0)$ & $3(50.0)$ \\
\hline t-AML & & $4(22.2)$ & $0(0.0)$ & $1(20.0)$ & $3(50.0)$ \\
\hline s-AML & & $1(5.6)$ & $1(14.3)$ & $0(0.0)$ & $0(0.0)$ \\
\hline White blood cell $\left(10^{9}\right.$ cells/L) & Median (SD) & $9.5(51.4)$ & $24.7(41.2)$ & $10.2(14.0)$ & $7.4(77.6)$ \\
\hline Cytogenetic prognosis & $N(\%)$ & & & & \\
\hline 1 & & $1(5.6)$ & $1(14.3)$ & $0(0.0)$ & $0(0.0)$ \\
\hline 2 & & $12(66.7)$ & $3(42.9)$ & $4(80.0)$ & $5(83.3)$ \\
\hline 3 & & $5(27.8)$ & $3(42.9)$ & $1(20.0)$ & $1(16.7)$ \\
\hline \multicolumn{6}{|l|}{ ELN } \\
\hline Favorable & & $3(16.7)$ & $1(14.3)$ & $2(40.0)$ & $0(0.0)$ \\
\hline Intermediate & & $10(55.6)$ & $3(42.9)$ & $2(40.0)$ & $5(83.3)$ \\
\hline Unfavorable & & $5(27.8)$ & $3(42.9)$ & $1(20.0)$ & $1(16.7)$ \\
\hline Blasts (blood) at diagnosis & Mean (SD) & $42.6(34.4)$ & $37.6(27.7)$ & $53.0(44.2)$ & $39.8(37.2)$ \\
\hline Blasts $(\mathrm{BM})$ at diagnosis & Mean (SD) & $63.7(29.2)$ & $56.9(24.9)$ & $73.0(34.8)$ & $63.8(32.0)$ \\
\hline
\end{tabular}

initially manually pre-gated, exported, and then analyzed with FLOCK algorithm.

Results obtained with manual gating were compared with results obtained with FLOCK. Annotated clusters were merged and graphically compared to the equivalent subsets obtained with manual gating (Figure 1A). Frequencies of FLOCK-gated and manually gated subsets of NK cells in HV samples with respect to CD56, CD57, KIR expression were comparable (Figure 1B). Thus, for each sample, proportions of NK cells within the different clusters with the two approaches were found to be fully consistent.

\section{Automated Gating with FLOCK Algorithm Evidences NK Subpopulations}

Natural killer cell maturation profiles in HV and AML patients were defined according to FLOCK output. For cluster annotation of FLOCK output data, we used an unsupervised hierarchical clustering with $\mathrm{MeV}$ (Figures 2A,B). Overall, the procedure enabled identification of five subsets of NK cells based on the expression of CD56, CD57, KIR, and NKG2A in both patients and healthy volunteers. NK cell differentiate from CD $56^{\text {bright }}$ to CD $56^{\text {dim }}$ phenotype. CD56 $6^{\text {bright }}$ phenotype then defines the most immature subset of circulating NK cells. In CD $56^{\mathrm{dim}} \mathrm{NK}$ cells, expression of NKG2A, KIR, and CD57 define several maturation stages (18). Automatic gating procedure with FLOCK enable identification of these different subsets of NK cells, with CD56 ${ }^{\text {bright }} \mathrm{NK}$ cells, and among CD56 ${ }^{\mathrm{dim}}$ cells, four subsets defined by the positivity or the negativity of KIR and CD57 (Figures 2A,B). In accordance with previous studies, KIR positivity inversely correlates with NKG2A expression, in both HV and AML patients $(18,29)$. We then considered the repartition of NK cells within the different clusters. On average, the percentage of CD56 $6^{\text {bright }}$ cells was found to be significantly lower in AML patients compared to HV $(1.3 \pm 3.2 \%$ vs. $6.4 \pm 5.8 \%$, respectively; $P=0.001$ ) (Figures $2 \mathrm{C}, \mathrm{D}$ ).

Overall, 2D mapping of NK maturation profiles enabled the visualization of high dimensional dataset as well as fast and reliable identification of NK cell subsets. With this unsupervised automated gating of NK cells with four parameters, the algorithm was able to distinguish all the NK subsets that were previously described in the literature, but did not identify any new population. Notably, NKG2A was not informative in NK cell cluster definition by the algorithm.

\section{AML Patients Present Distinct Maturation Profiles}

Patients and $\mathrm{HV}$ were clustered according to the percentages of $\mathrm{NK}$ cells represented in the $\mathrm{CD} 56^{\text {bright }}, \mathrm{KIR}^{-} / \mathrm{CD} 57^{-}$, $\mathrm{KIR}^{+} / \mathrm{CD}^{-} 7^{-}, \mathrm{KIR}^{-} / \mathrm{CD} 57^{+}, \mathrm{KIR}^{+} / \mathrm{CD} 57^{+}$clusters with $\mathrm{MeV}$ using unsupervised hierarchical clustering (HClust, Pearson correlation) (Figure 3). This representation allowed defining three distinct groups of patients. The first group of patients $(N=7)$ presented a NK cell maturation profile with $50 \%$ (range: $40-67 \%$ ) NK cells in the cluster $\mathrm{KIR}^{-} / \mathrm{CD} 57^{-}$cluster. Considering the repartition of $\mathrm{NK}$ cells within the different clusters, there was no significant difference between this group and HV. The second group of patients $(N=5)$ presented an intermediate maturation 
A
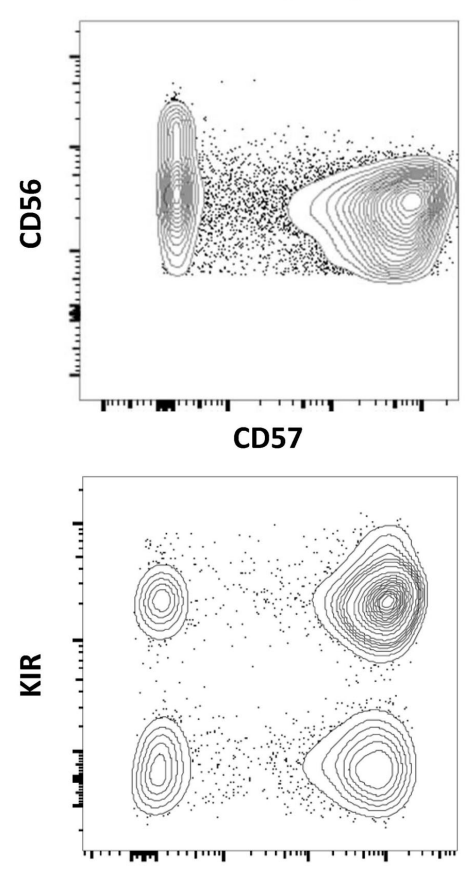

CD57
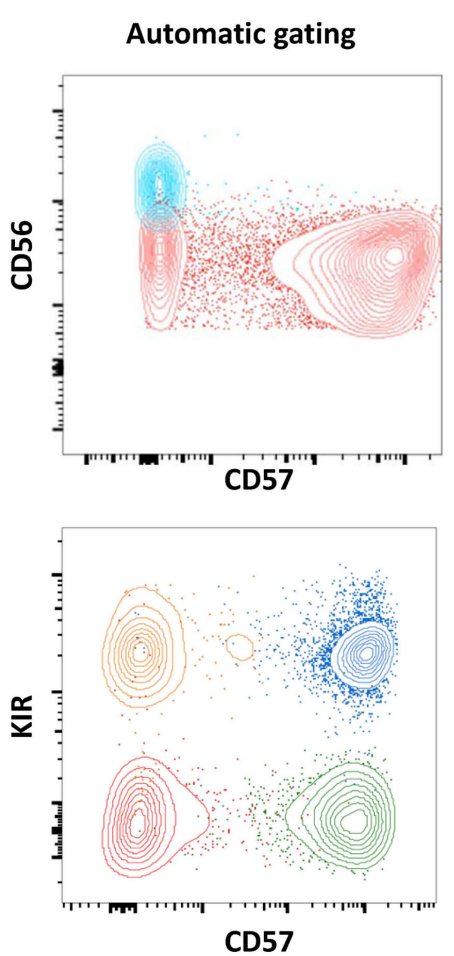

B

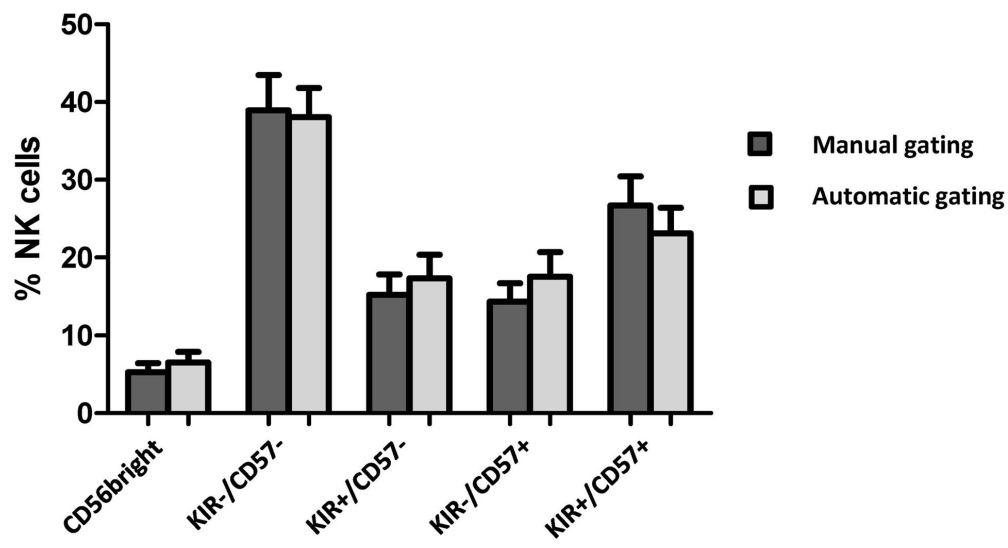

FIGURE 1 | Comparison of manually gated data and FLOCK analysis. (A) NK clusters were automatically defined by FLOCK and manually annotated as CD56 ${ }^{\text {bright }}$ or CD56 ${ }^{\text {dim }}$ NK cells, among which four additional subsets were defined according to KIR and CD57 expression. For a given sample, clusters were defined by FLOCK. The clusters were merged when corresponding to the same NK subpopulation and visualized with FlowJo for comparison with manual gating. Each color represents the merging of clusters corresponding to the same population. (B) Frequencies of FLOCK and manually gated subsets of NK cells with respect to CD56, CD57, KIR expression. Data are presented as mean \pm SD of Healthy Volunteers $(N=18)$.

profile, with $43 \%$ (range: $30-52 \%$ ) NK cells in the $\mathrm{KIR}^{-} / \mathrm{CD} 57^{-}$ cluster and $37 \%$ (range: $28-48 \%$ ) NK cells in the $\mathrm{KIR}^{+} / \mathrm{CD} 57^{+}$ cluster. For this group, the proportion of NK cells in the CD56 $6^{\text {bright }}$ cluster was significantly lower than $\operatorname{HV}(P=0.05)$. Of note, the apparent high frequency of cells in the cluster $\mathrm{KIR}^{+} / \mathrm{CD} 57^{+}$ was not significantly different from HV. The third group of patients $(N=6)$ presented an hyper-maturation profile, with proportions of NK cells of $13 \%$ (range: $7-24 \%$ ) NK cells in the $\mathrm{KIR}^{-} / \mathrm{CD}^{-} 7^{-}$cluster and 58\% (range: $34-83 \%$ ) NK cells in the $\mathrm{KIR}^{+} / \mathrm{CD} 57^{+}$cluster. For this group, the proportion of $\mathrm{NK}$ cells in the $\mathrm{KIR}^{-} / \mathrm{CD} 57^{-}$cluster was significantly lower than $\mathrm{HV}(P<0.05)$ whereas the proportion of NK cells in the $\mathrm{KIR}^{+} / \mathrm{CD}^{+} 7^{+}$cluster was significantly higher $(P<0.01)$.

In conclusion, we observed that NK cells in AML patients display marked differences compared to HV, with a strong interindividual variability, defining three distinct groups of patients according to NK maturation profiles.

\section{DISCUSSION}

Accumulating evidence highlights NK cell parameters as potential prognostic factors in cancer patients, which provides a strong 
A
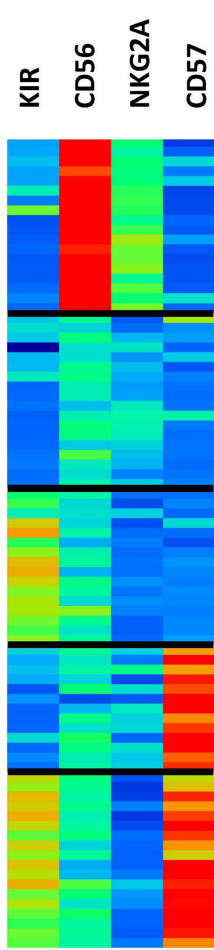

CD56 bright

CD56 ${ }^{\operatorname{dim}} / \mathrm{KIR} / \mathrm{CD} 57$

$\mathrm{CD}^{\mathrm{dim}} / \mathrm{KIR}^{+} / \mathrm{CD} 57$

$\mathrm{CD}^{\mathrm{dim}} / \mathrm{KIR}^{-} / \mathrm{CD}^{\mathrm{C}} 7^{+}$

CD56 ${ }^{\text {dim }} / \mathrm{KIR}^{+} / \mathrm{CD}^{+} 7^{+}$

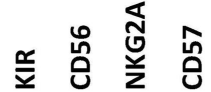

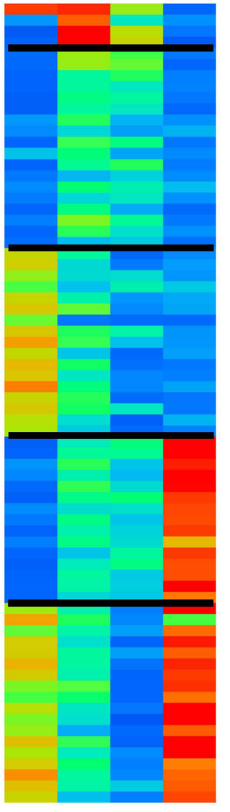

CD56 $6^{\text {bright }}$

CD56 dim / KIR/ CD57

CD56 dim $/ \mathrm{KIR}^{+} / \mathrm{CD} 57$

CD56 ${ }^{\text {dim }} /$ KIR $^{-} /$CD57 $^{+}$

$\mathrm{CD}^{\mathrm{dim}} / \mathrm{KIR}^{+} / \mathrm{CD}^{+} 7^{+}$
Low expression

C

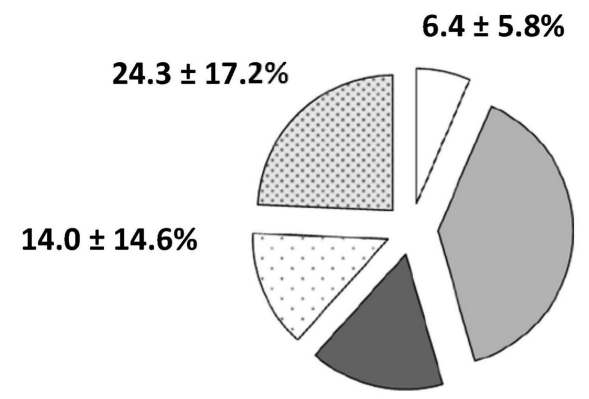

$16.0 \pm 14.6 \%$

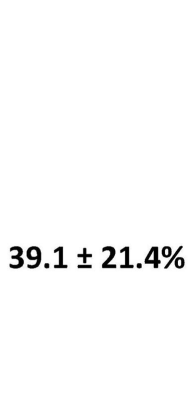

$39.1 \pm 21.4 \%$

\section{CD56 bright}

CD56 dim/KIR-/CD57-

CD56 dim/KIR+/CD57-

High expression

D

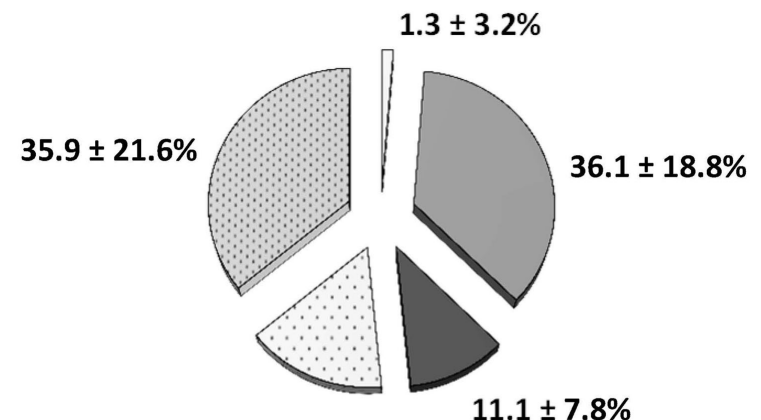

$15.7 \pm 11.0 \%$

$11.1 \pm 7.8 \%$

FIGURE 2 | NK maturation in HV and AML patients. NK maturation profiles in HV (A) and AML patients (B) were defined according to FLOCK output and NK subpopulations were represented using Manhattan Hierarchical Clustering based on CD56, KIR, NKG2A, and CD57 expression. Five clusters were defined; each individual is represented in three to five clusters, depending on the presence or absence of NK cells in the different clusters. Percentages of NK cells within clusters are presented as mean $\pm \mathrm{SD}$ in $\mathrm{HV}$ (C) and $\mathrm{AML}$ (D).

rationale for developing therapeutic strategies aiming at restoring NK cell functions (4-9). However, reaching this point warrants better characterization of NK cell alterations in cancer patients as well as elucidation of the mechanisms involved $(30,31)$.

Among important parameters involved in NK cell functions, the maturation process is of particular importance; since, depending on the maturation stage NK cells will gain or lose important functions, such as migration capacities, effector functions, response to cytokines, proliferative capacities, IFN- $\gamma$ production, or cytotoxic activity $(8,14,32)$. All these functions are absolutely required for a functional effect against tumor cells. Thus alteration of the maturation process is likely to 


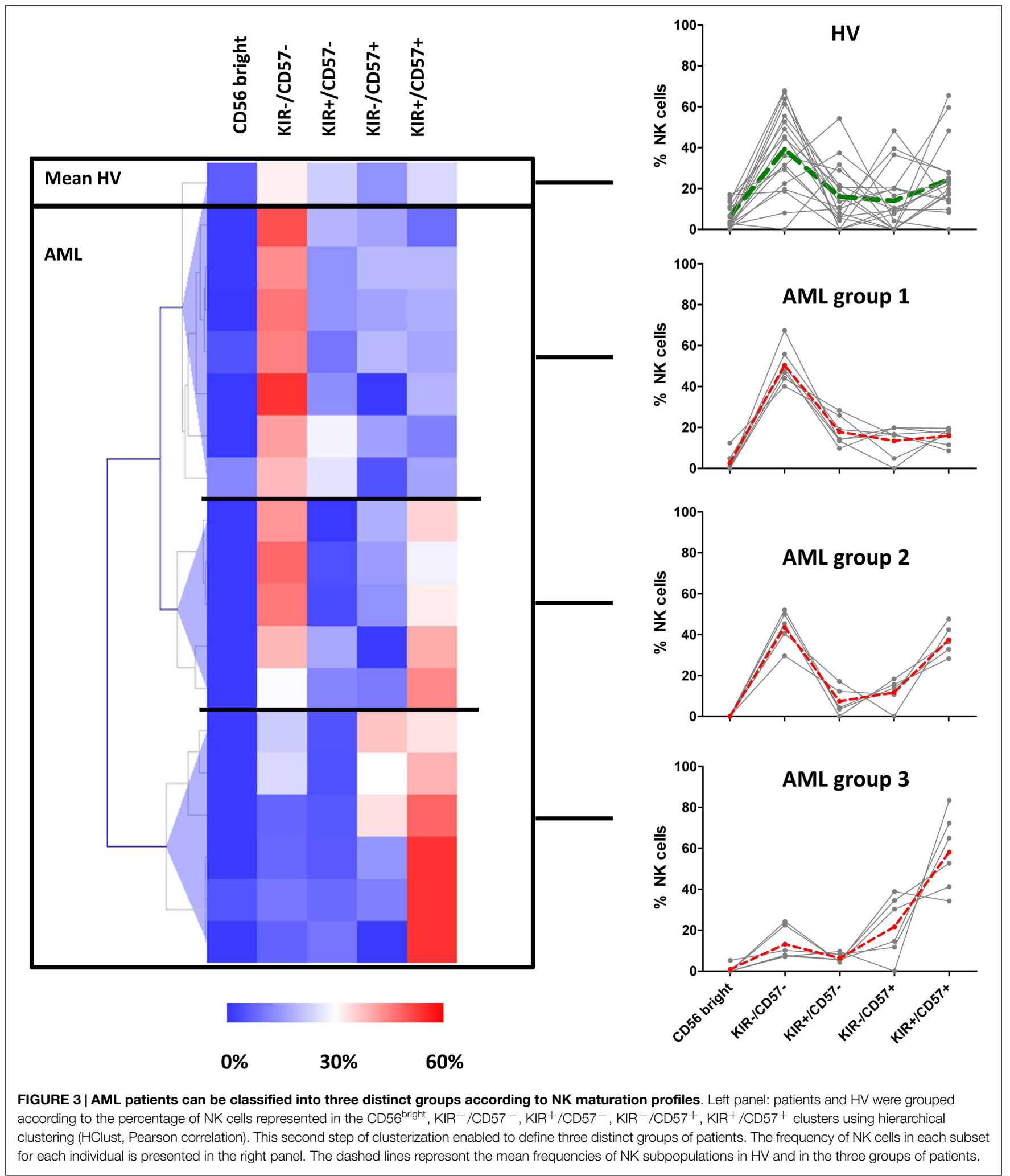

impact NK cell functions, with direct consequences on patients' survival (33).

Natural killer cell maturation is a multistep process marked by differential expression of many markers, among which CD56,
NKG2A, KIR, and CD57 are of particular importance (18). NK cell subsets can also be defined according to the expression of CD16 and CD56. For instance, it has been described discrete stages of NK cell differentiation. First, CD56 $6^{\text {bright }}$ NK cells expressing low 
levels of CD16 correspond to a transition between early immature CD56 ${ }^{\text {bright }} \mathrm{CD}^{-} 6^{-} \mathrm{NK}$ cells and CD56 ${ }^{\mathrm{dim}} \mathrm{CD} 16^{+} \mathrm{NK}$ cells (34). Variations of NK cells in these different compartments have been described in several clinical conditions such as HIV infection and in aging (13). In addition, another NK cell population of $\mathrm{CD} 6^{-} \mathrm{CD} 16^{+}$cells has been described and found expanded in particular pathological conditions such as HIV or hepatitis $\mathrm{C}$ virus infection $(35,36)$. Although these discrete stages have been evidenced, the functions of these cells remain elusive, particularly in the context of AML.

Whether NK maturation is impacted by the close proximity with leukemic blasts is an important question. Under physiological conditions, circulating NK cells differentiate from CD56 $6^{\text {bright }}$ to CD56 ${ }^{\text {dim }}$ phenotype. Then NK cells lose NKG2A expression, and gain KIR expression. CD57 is acquired at later stages of differentiation, and defines a subset of NK cells with low proliferative capacities and high cytotoxic potential $(16,18)$. In our study, we show that NK cells in AML patients present marked differences compared to Healthy Volunteers. The proportion of $\mathrm{CD} 57^{+} \mathrm{NK}$ cells is increased in one-third of patients, at the expense of less mature NK subsets, with a drastic decrease of immature NK cells. Although $\mathrm{CD}_{57}{ }^{+} \mathrm{NK}$ cells have been described as the most cytotoxic subset of NK cells, in the context of AML, we still need to check whether these cells display efficient cytotoxic activity on cancer target cells. In addition, the impact of these extreme maturation profiles on clinical outcome warrants further exploration on a larger cohort of patients.

Natural killer cell maturation has been studied in human breast and lung cancer $(37,38)$. In contrast to our study, tumorinfiltrating NK cells display an immature phenotype, with high percentages of CD56 $6^{\text {bright }} \mathrm{NK}$ cells compared to healthy tissues. A notable difference in our study is that we analyzed peripheral blood cells, whereas the previously cited studies were done with infiltrating NK cells. Mamessier et al. hypothesized that NK cells were de-differentiated rather than immature cells; this could explain the high proportion of CD56 $6^{\text {bright }}$ in tumor tissue, without direct impact on central $\mathrm{NK}$ maturation or migration of the most immature cells on the tumor site. One additional difference in the context of AML is that NK cells maturate in close contact with tumor cells. This could explain the high proportion of highly maturated NK cells. However, some authors also described CD56 ${ }^{\mathrm{dim}} \mathrm{CD} 57^{+}$enrichment in tumor-infiltrated lymph nodes in patients with metastatic melanoma, with significant impact on patients' survival (33).

Technical advances in flow and mass cytometry now enable the dissection of NK cell biology with high precision, with the subsequent need for tools adapted to the analysis of datasets with unprecedented dimensionality $(21,25,39)$. In our study, we used an automated procedure using the FLOCK algorithm and hierarchical clustering, which enabled unsupervised identification of NK subsets and patients profiling based on NK parameters. Automatic gating algorithms are powerful and reliable tools adapted to high dimensional dataset analysis $(25,40)$ with potential limitations highlighted in the case of rare populations $(40,41)$. In the case of immunomonitoring studies on large cohorts of patients, the development of such approaches is of primary importance for data analysis standardization. First, the high number of subjects included in these studies requires automated gating in order to reduce the time of analysis. Second, visualization of all the clusters allows fast and unsupervised identification of cell populations. Moreover, the hierarchical classification of patients according to maturation profiles enables the discovery of distinct patterns or specific subgroups among patients. The clinical consequences of such observations should be evaluated on larger cohorts of patients. Considering the potential impact of NK maturation on clinical outcome, NK cell maturation profiling might be informative in prognostic immune signatures and may find applications in patients' stratification at diagnosis.

\section{AUTHOR CONTRIBUTIONS}

A-SC: design of the work, data analysis and interpretation, statistical analyses and interface with biological findings, redaction of the article, revisions and final approval of the version to be published, agreement of all aspects of the work in ensuring that questions related to the accuracy or integrity of any part of the work are appropriately investigated and resolved. SG: data interpretation, statistical analyses and interface with biological findings, drafting and revisions of the work, final approval of the version to be published, agreement of all aspects of the work in ensuring that questions related to the accuracy or integrity of any part of the work are appropriately investigated and resolved. FG-R: data interpretation, statistical analyses and interface with biological findings, drafting and revisions of the work, final approval of the version to be published, agreement of all aspects of the work in ensuring that questions related to the accuracy or integrity of any part of the work are appropriately investigated and resolved. $\mathrm{SH}$ : data acquisition and interpretation, revisions of the work, final approval of the version to be published, agreement of all aspects of the work in ensuring that questions related to the accuracy or integrity of any part of the work are appropriately investigated and resolved. FO: data analysis and interpretation, drafting of the work and final approval of the version to be published, agreement of all aspects of the work in ensuring that questions related to the accuracy or integrity of any part of the work are appropriately investigated and resolved. DB: conception and design of the work, revisions of the work and final approval of the version to be published, agreement of all aspects of the work in ensuring that questions related to the accuracy or integrity of any part of the work are appropriately investigated and resolved. NV: conception and design of the work, revisions of the work and final approval of the version to be published, agreement of all aspects of the work in ensuring that questions related to the accuracy or integrity of any part of the work are appropriately investigated and resolved. CA: conception and design of the work, revisions of the work and final approval of the version to be published, agreement of all aspects of the work in ensuring that questions related to the accuracy or integrity of any part of the work are appropriately investigated and resolved. CF: conception and design of the work, data analysis and interpretation, article redaction, revisions of the work and final approval of the version to be published, agreement of all aspects of the work in ensuring that questions related to the accuracy or integrity of any part of the work are appropriately investigated and resolved. DO: conception and design of the work, interpretation of data for the work, revisions of the work and final approval of 
the version to be published, agreement of all aspects of the work in ensuring that questions related to the accuracy or integrity of any part of the work are appropriately investigated and resolved.

\section{ACKNOWLEDGMENTS}

The authors thank Beckman Coulter for their technical advices and for providing the antibodies used in this study. The authors

\section{REFERENCES}

1. Moretta L, Bottino C, Pende D, Vitale M, Mingari MC, Moretta A. Human natural killer cells: molecular mechanisms controlling NK cell activation and tumor cell lysis. Immunol Lett (2005) 100(1):7-13. doi:10.1016/j.imlet.2005. 07.004

2. Vivier E, Raulet DH, Moretta A, Caligiuri MA, Zitvogel L, Lanier LL, et al. Innate or adaptive immunity? The example of natural killer cells. Science (2011) 331(6013):44-9. doi:10.1126/science.1198687

3. Vivier E, Ugolini S, Blaise D, Chabannon C, Brossay L. Targeting natural killer cells and natural killer T cells in cancer. Nat Rev Immunol (2012) 12(4):239-52. doi:10.1038/nri3174

4. Costello RT, Fauriat C, Sivori S, Marcenaro E, Olive D. NK cells: innate immunity against hematological malignancies? Trends Immunol (2004) 25(6):328-33. doi:10.1016/j.it.2004.04.005

5. Delahaye NF, Rusakiewicz S, Martins I, Menard C, Roux S, Lyonnet L, et al. Alternatively spliced NKp30 isoforms affect the prognosis of gastrointestinal stromal tumors. Nat Med (2011) 17(6):700-7. doi:10.1038/nm.2366

6. Fauriat C, Just-Landi S, Mallet F, Arnoulet C, Sainty D, Olive D, et al. Deficient expression of NCR in NK cells from acute myeloid leukemia: evolution during leukemia treatment and impact of leukemia cells in NCRdull phenotype induction. Blood (2007) 109(1):323-30. doi:10.1182/blood-2005-08-027979

7. Fauriat C, Marcenaro E, Sivori S, Rey J, Gastaut JA, Moretta A, et al. Natural killer cell-triggering receptors in patients with acute leukaemia. Leuk Lymphoma (2003) 44(10):1683-9. doi:10.080/1042819031000104006

8. Khaznadar Z, Boissel N, Agaugue S, Henry G, Cheok M, Vignon M, et al. Defective NK cells in acute myeloid leukemia patients at diagnosis are associated with blast transcriptional signatures of immune evasion. J Immunol (2015) 195(6):2580-90. doi:10.4049/jimmunol.1500262

9. Pasero C, Gravis G, Granjeaud S, Guerin M, Thomassin-Piana J, Rocchi P, et al. Highly effective NK cells are associated with good prognosis in patients with metastatic prostate cancer. Oncotarget (2015) 6:14360-73. doi:10.18632/ oncotarget.3965

10. Ascierto ML, Idowu MO, Zhao Y, Khalak H, Payne KK, Wang XY, et al. Molecular signatures mostly associated with NK cells are predictive of relapse free survival in breast cancer patients. J Transl Med (2013) 11:145. doi:10.1186/ 479-5876-11- 145

11. Menard C, Blay JY, Borg C, Michiels S, Ghiringhelli F, Robert C, et al. Natural killer cell IFN-gamma levels predict long-term survival with imatinib mesylate therapy in gastrointestinal stromal tumor-bearing patients. Cancer Res (2009) 69(8):3563-9. doi:10.1158/0008-5472.CAN-08-3807

12. Chretien AS, Le Roy A, Vey N, Prebet T, Blaise D, Fauriat C, et al. Cancerinduced alterations of NK-mediated target recognition: current and investigational pharmacological strategies aiming at restoring NK-mediated anti-tumor activity. Front Immunol (2014) 5:122. doi:10.3389/fimmu.2014.00122

13. Sanchez-Correa B, Campos C, Pera A, Bergua JM, Arcos MJ, Banas H, et al. Natural killer cell immunosenescence in acute myeloid leukaemia patients: new targets for immunotherapeutic strategies? Cancer Immunol Immunother (2015). doi:10.1007/s00262-015-1720-6

14. Hayakawa Y, Smyth MJ. CD27 dissects mature NK cells into two subsets with distinct responsiveness and migratory capacity. J Immunol (2006) 176(3):1517-24. doi:10.4049/jimmunol.176.3.1517

15. Chiossone L, Chaix J, Fuseri N, Roth C, Vivier E, Walzer T. Maturation of mouse NK cells is a 4-stage developmental program. Blood (2009) 113(22):5488-96. doi:10.1182/blood-2008-10-187179

16. Lopez-Verges S, Milush JM, Pandey S, York VA, Arakawa-Hoyt J, Pircher H, et al. CD57 defines a functionally distinct population of mature NK cells in thank the CRCM the Immunomonitoring platform and the CRCM Systems Biology platform for their valued contributions to this work.

\section{FUNDING}

This work has been financially supported by the INCa and the Canceropole PACA.

the human CD56dimCD16+ NK-cell subset. Blood (2010) 116(19):3865-74. doi:10.1182/blood-2010-04-282301

17. Yu J, Freud AG, Caligiuri MA. Location and cellular stages of natural killer cell development. Trends Immunol (2013) 34(12):573-82. doi:10.1016/j.it.2013. 07.005

18. Bjorkstrom NK, Riese P, Heuts F, Andersson S, Fauriat C, Ivarsson MA, et al. Expression patterns of NKG2A, KIR, and CD57 define a process of CD56dim NK-cell differentiation uncoupled from NK-cell education. Blood (2010) 116(19):3853-64. doi:10.1182/blood-2010-04-281675

19. Cooper MA, Fehniger TA, Caligiuri MA. The biology of human natural killer-cell subsets. Trends Immunol (2001) 22(11):633-40. doi:10.1016/S14714906(01)02060-9

20. Frey M, Packianathan NB, Fehniger TA, Ross ME, Wang WC, Stewart CC, et al. Differential expression and function of L-selectin on CD56bright and CD56dim natural killer cell subsets. J Immunol (1998) 161(1):400-8.

21. Horowitz A, Strauss-Albee DM, Leipold M, Kubo J, Nemat-Gorgani N, Dogan $\mathrm{OC}$, et al. Genetic and environmental determinants of human NK cell diversity revealed by mass cytometry. Sci Transl Med (2013) 5(208):208ra145. doi:10. 1126/scitranslmed.3006702

22. Lo K, Hahne F, Brinkman RR, Gottardo R. flowClust: a bioconductor package for automated gating of flow cytometry data. BMC Bioinformatics (2009) 10:145. doi:10.1186/471-2105-10-145

23. Qiu P, Simonds EF, Bendall SC, Gibbs KD Jr, Bruggner RV, Linderman MD, et al. Extracting a cellular hierarchy from high-dimensional cytometry data with SPADE. Nat Biotechnol (2011) 29(10):886-91. doi:10.1038/nbt.991

24. Amir el AD, Davis KL, Tadmor MD, Simonds EF, Levine JH, Bendall SC, et al. viSNE enables visualization of high dimensional single-cell data and reveals phenotypic heterogeneity of leukemia. Nat Biotechnol (2013) 31(6):545-52. doi:10.1038/nbt. 2594

25. Levine JH, Simonds EF, Bendall SC, Davis KL, Amir ED, Tadmor MD, et al. Data-driven phenotypic dissection of AML reveals progenitor-like cells that correlate with prognosis. Cell (2015) 162:1-14. doi:10.1016/j.cell.2015.05.047

26. Qian Y, Wei C, Eun-Hyung Lee F, Campbell J, Halliley J, Lee JA, et al. Elucidation of seventeen human peripheral blood B-cell subsets and quantification of the tetanus response using a density-based method for the automated identification of cell populations in multidimensional flow cytometry data. Cytometry B Clin Cytom (2010) 78(Suppl 1):S69-82. doi:10.1002/cyto.b.20554

27. Gentleman RC, Carey VJ, Bates DM, Bolstad B, Dettling M, Dudoit S, et al. Bioconductor: open software development for computational biology and bioinformatics. Genome Biol (2004) 5(10):R80. doi:10.1186/gb-2004-5-10-r80

28. Saeed AI, Sharov V, White J, Li J, Liang W, Bhagabati N, et al. TM4: a free, opensource system for microarray data management and analysis. Biotechniques (2003) 34(2):374-8.

29. Fauriat C, Andersson S, Bjorklund AT, Carlsten M, Schaffer M, Bjorkstrom NK, et al. Estimation of the size of the alloreactive NK cell repertoire: studies in individuals homozygous for the group A KIR haplotype. J Immunol (2008) 181(9):6010-9. doi:10.4049/jimmunol.181.9.6010

30. Loza MJ, Perussia B. Final steps of natural killer cell maturation: a model for type 1-type 2 differentiation? Nat Immunol (2001) 2(10):917-24. doi:10.1038/ ni01-917

31. Vasu S, Caligiuri MA. Targeted immunotherapy for acute myeloid leukemia Best Pract Res Clin Haematol (2011) 24(4):533-40. doi:10.1016/j.beha.2011.09. 001

32. Cooley S, Weisdorf DJ, Guethlein LA, Klein JP, Wang T, Le CT, et al. Donor selection for natural killer cell receptor genes leads to superior survival after unrelated transplantation for acute myelogenous leukemia. Blood (2010) 116(14):2411-9. doi:10.1182/blood-2010-05-283051 
33. Ali TH, Pisanti S, Ciaglia E, Mortarini R, Anichini A, Garofalo C, et al. Enrichment of CD56(dim)KIR + CD57 + highly cytotoxic NK cells in tumourinfiltrated lymph nodes of melanoma patients. Nat Commun. (2014) 5:5639. doi: $10.1038 /$ ncomms6639

34. Beziat V, Duffy D, Quoc SN, Le Garff-Tavernier M, Decocq J, Combadiere $B$, et al. CD56brightCD16+ NK cells: a functional intermediate stage of NK cell differentiation. J Immunol (2011) 186(12):6753-61. doi:10.4049/jimmunol. 1100330

35. Alter G, Teigen N, Davis BT, Addo MM, Suscovich TJ, Waring MT, et al. Sequential deregulation of NK cell subset distribution and function starting in acute HIV-1 infection. Blood (2005) 106(10):3366-9. doi:10.1182/blood-200503- 1100

36. Golden-Mason L, Madrigal-Estebas L, McGrath E, Conroy MJ, Ryan EJ, Hegarty JE, et al. Altered natural killer cell subset distributions in resolved and persistent hepatitis $\mathrm{C}$ virus infection following single source exposure. Gut (2008) 57(8):1121-8. doi:10.1136/gut.2007.130963

37. Mamessier E, Sylvain A, Thibult ML, Houvenaeghel G, Jacquemier J, Castellano $\mathrm{R}$, et al. Human breast cancer cells enhance self tolerance by promoting evasion from NK cell antitumor immunity. J Clin Invest (2011) 121(9):3609-22. doi:10. $1172 /$ JCI 45816

38. Carrega P, Morandi B, Costa R, Frumento G, Forte G, Altavilla G, et al. Natural killer cells infiltrating human nonsmall-cell lung cancer are enriched in CD56 bright CD16(-) cells and display an impaired capability to kill tumor cells. Cancer (2008) 112(4):863-75. doi:10.1002/cncr.23239
39. Bendall SC, Simonds EF, Qiu P, Amir el AD, Krutzik PO, Finck R, et al Single-cell mass cytometry of differential immune and drug responses across a human hematopoietic continuum. Science (2011) 332(6030):687-96. doi:10. $1126 /$ science. 1198704

40. Aghaeepour N, Finak G, Hoos H, Mosmann TR, Brinkman R, Gottardo R, et al. Critical assessment of automated flow cytometry data analysis techniques. Nat Methods (2013) 10(3):228-38. doi:10.1038/nmeth.2365nmeth

41. O’Neill K, Aghaeepour N, Spidlen J, Brinkman R. Flow cytometry bioinformatics. PLoS Comput Biol (2013) 9(12):e1003365. doi:10.1371/journal.pcbi. 1003365

Conflict of Interest Statement: The authors declare that the research was conducted in the absence of any commercial or financial relationships that could be construed as a potential conflict of interest.

Copyright (C) 2015 Chretien, Granjeaud, Gondois-Rey, Harbi, Orlanducci, Blaise, Vey, Arnoulet, Fauriat and Olive. This is an open-access article distributed under the terms of the Creative Commons Attribution License (CC BY). The use, distribution or reproduction in other forums is permitted, provided the original author(s) or licensor are credited and that the original publication in this journal is cited, in accordance with accepted academic practice. No use, distribution or reproduction is permitted which does not comply with these terms. 